\title{
Triptych of the Hermit Saints: pneumococcal polysaccharide vaccines for the elderly
}

This article was published in the following Dove Press journal: Risk Management and Healthcare Policy

\author{
Ger T Rijkers ${ }^{1,2}$ \\ Laura IE Yousif' \\ Simone MC Spoorenberg ${ }^{3}$ \\ Frans J van Overveld' \\ 'Department of Science, University \\ College Roosevelt, Middelburg, the \\ Netherlands; ${ }^{2}$ Department of Medical \\ Microbiology and Immunology, \\ St. Antonius Hospital, Nieuwegein, \\ the Netherlands; ${ }^{3}$ Department \\ of Internal Medicine, St Antonius \\ Hospital, Nieuwegein, the Netherlands
}

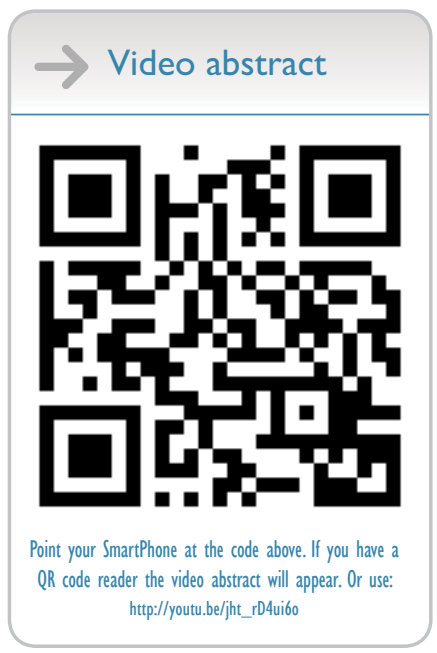

Correspondence: Ger T Rijkers Department of Science, University College Roosevelt, P.O. Box 94, Middelburg $4330 \mathrm{AB}$, the Netherlands Tel +3 I 0 II 8655500

Fax +310118655508 Email g.rijkers@ucr.nl

\begin{abstract}
Pneumococcal pneumonia is a serious disease with considerable morbidity and mortality in the elderly. Despite adequate antibiotic treatment, the long-term mortality of pneumococcal pneumonia remains high. Preventive measures in the form of vaccination, therefore, are warranted. Twenty-three-valent polysaccharide vaccines have a broad coverage but limited efficacy. Pneumococcal conjugate vaccines have been shown in children to be able to prevent invasive and mucosal pneumococcal diseases. It should be realized that the serotype composition of current pneumococcal conjugate vaccines is not tailored for the elderly, and that replacement disease can occur. Yet, the current 13-valent conjugate vaccine has been shown to protect against infections with vaccine serotypes. Long-term mortality of pneumococcal pneumonia should be included in policy making about the introduction of these vaccines for the elderly.
\end{abstract}

Keywords: pneumonia, Streptococcus pneumoniae, vaccination, elderly, conjugate vaccines, cost-effectiveness

\section{Introduction Pneumococcal disease}

Streptococcus pneumoniae is an encapsulated Gram-positive, facultative anaerobic bacterium. It can cause mucosal infections such as otitis media, sinusitis, and nonbacteremic pneumonia, and also invasive diseases such as bacteremia, bacteremic pneumonia, and meningitis. In terms of frequency, otitis media is, by far, the most common pneumococcal infection, with every child having gone through 1 or (in many cases) more episodes. ${ }^{1}$ The World Health Organization estimates that annually 476,000 (range 333,000-529,000) children under 5 years of age die due to pneumococcal infections, mainly pneumonia. ${ }^{2}$ Global data on the incidence of invasive pneumococcal disease in the elderly suggest a similarly high burden. ${ }^{3}$ Both the mucosal and the invasive forms of pneumococcal diseases therefore have received considerable attention in the medical literature. The New England Journal of Medicine has, since 1812, published 21,112 articles, which can be retrieved using "pneumonia" as the search term: 1734 with otitis media, 15,018 on meningitis, and 6710 on sepsis (accessed on September 25, 2017). The Lancet, since 1830, shows remarkable comparable numbers: pneumonia 22,867, otitis media 2,184, meningitis 10,543, and sepsis 9,642 (accessed on September 25, 2017). Clearly, pneumonia is represented most prominently in the medical literature as disease manifestation of infection with $S$. pneumoniae. 
Young children, who have a high nasopharyngeal carriage rate, are most probably the reservoir from which $S$. pneumoniae spreads to the elderly population. Dochez and Avery have already speculated about the transmission of pneumococcal disease:

\begin{abstract}
Although there are in the literature instances of the apparent contagiousness of lobar pneumonia, it has been commonly assumed that most cases of the disease represent probable infection with a pneumococcus dwelling during health on the buccal mucous membrane of normal human beings.
\end{abstract}

They thus suggest that most infections would result from bacteria, already carried in the nasopharyngeal area. Why a healthy carrier at a given point in time becomes infected could be due to "a sudden accession of virulence of the pneumococcus, or unusual depression of resistance of the individual "; the latter condition is now termed immunocompromised. Through either one or both of these mechanisms, "this organism, the pneumococcus, is supposed to be able to penetrate the lungs and set up disease". ${ }^{4}$

\section{Etiology}

In the past, community-acquired pneumonia (CAP) was considered in practice to be equivalent to pneumococcal pneumonia. Indeed, in the 1930s, before the introduction of antibiotics, in over $95 \%$ of cases, S. pneumoniae could be cultured from patients with CAP. ${ }^{5}$ Nowadays, despite greatly improved diagnostic techniques, S. pneumoniae can be demonstrated in, on average, $25 \%$ (range $12 \%-68 \%$ ) of cases. ${ }^{6,7}$

A variety of diagnostic tests, including sputum culture, blood culture, urine antigen test, and serological responses, can be performed to identify the causative agent of CAP. ${ }^{8} \mathrm{An}$ expectorated sputum sample can be cultured for respiratory pathogens or be analyzed by molecular methods. Similarly, blood cultures can be performed in case of a bacteremic pneumonia. Urinalysis can detect the presence of pneumococcal cell wall polysaccharides or serotype-specific capsular polysaccharides. ${ }^{9}, 10 \mathrm{An}$ indirect, but specific, method to investigate the involvement of $S$. pneumoniae in CAP is the analysis of the serological response, that is, the increase in serotype-specific antibodies during the course of disease. ${ }^{11}$ However, the latter test cannot be used during the diagnostic phase because it requires a blood sample $>10$ days after the onset of disease.

A comprehensive microbiological and virological analysis of the biological specimens described above reveals the varied etiology of CAP. ${ }^{12-14}$ Viruses such as influenza and respiratory syncytial virus can cause CAP. Major bacterial causes for CAP (in Europe) apart from S. pneumoniae, in descending order of importance, are as follows: Chlamydia species, Mycoplasma pneumoniae, Chlamydophila pneumoniae, Haemophilus influenzae, Legionella pneumophila, Pseudomonas aeruginosa, Staphylococcus aureus, Chlamydophila psittaci, Coxiella burnetii, and Moraxella catarrhalis..$^{15,16}$

The data in Figure 1 show that, even when using an extensive diagnostic toolset, including serological responses, in $25 \%$ of CAP patients, no causative agent can be identified. An alternative but invasive diagnostic tool for establishing the causative agent for CAP is transthoracic needle aspiration (TTNA) biopsy. This is a procedure that has been used from as early as 1883 to diagnose pulmonary malignancies. ${ }^{17}$ The biopsy is taken after a chest radiography has been used to identify consolidation adjacent to the chest wall. Additionally, anatomic landmarks are used to indicate where the needle

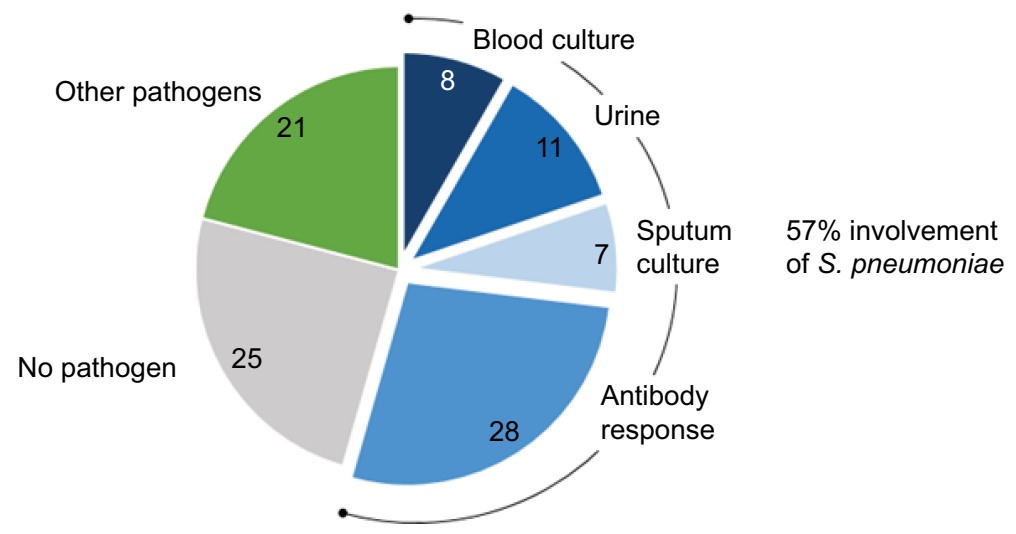

Figure I Microbiological etiology of CAP. A total of 349 CAP patients from 2 clinical trials were enrolled. Conventional microbiological analysis (blood culture, urinalysis, and sputum culture) identified Streptococcus pneumoniae as a causative organism. Determination of serotype-specific antibodies in serum showed S. pneumoniae involvement in an additional $28 \%$ of patients. Most commonly identified pathogens in the other pathogens category were Coxiella burnetti, Legionella species, Mycoplasma pneumoniae, Haemophilus influenzae, Chlamydophila psittaci, influenza A virus, and Staphylococcus aureus. Data from van Mens et al."

Abbreviation: CAP, community-acquired pneumonia. 
should be inserted. The needle should be inserted immediately below the inferior angle of the scapula for lower lobe consolidation, through the anterior chest wall for upper lobe consolidation, and through the intercostal space lateral to the right nipple for right middle lobe consolidation. A very big advantage of this procedure is its minimally invasive nature, making it a desired alternative to surgical intervention. ${ }^{18}$ The presence of a single pathogen in diseased tissue of patients with pneumonia and the absence of this in the same tissue in healthy control subjects is the most convincing evidence of the etiology of pneumonia. ${ }^{19}$ Due to TTNA's high specificity and relatively high yield, it is the most acceptable and uncontaminated single way of determining the etiology of pneumonia. The use of CT for guidance allows for good visualization and detection of smaller lesions as well. However, TTNA is not a widely practiced procedure due to concerns regarding the potential adverse effects. These potential complications include, but are not limited to, pneumothorax, hemorrhage, and air embolism. A postprocedure pneumothorax is the most common nonfatal complication, usually caused by large bullae in the path of the biopsy.

Although $S$. pneumoniae is a single bacterial species for the immune system and, therefore, for host defense and susceptibility, it is a collection of different bacterial species because of its polysaccharide capsule. Currently, 93 different types of polysaccharide capsules of $S$. pneumoniae are known to exist, subdivided in serologically distinguishable groups and types. ${ }^{20}$ The 23 most prevalent serotypes are responsible for $80 \%-90 \%$ of all invasive pneumococcal diseases. ${ }^{21}$ It must be kept in mind that great variation exists in serotype prevalence for the type of pneumococcal disease, the age category of risk groups, and geographical region. Pneumococcal serotypes 1 and 3 appear to have preferences for the lung, while serotypes/groups 6, 10, and 23 more often cause meningitis. ${ }^{22,23}$ In an observational study, the serotype distribution in isolates from patients with invasive pneumococcal disease was found to differ between children (common serotypes 4, 6B, 19F, and 18C) and adults where serotypes 3, 4, and 9V dominated. ${ }^{24}$ Globally, serotypes 14 , $19 \mathrm{~A}$, and 19F are most common in children, while in adults and the elderly, serotypes $3,6 \mathrm{~A}, 7 \mathrm{~F}$, and 19A are prevalent. ${ }^{25}$

The most frequent pneumococcal serotypes in Europe are $1,3,7 \mathrm{~F}, 14$, and $19 \mathrm{~A}$, but rather big differences can be found between European countries. ${ }^{26}$ On a global scale, the regional differences are much bigger. These aspects are important for the development of pneumococcal vaccines (see also below), because these vaccines should cover as many serotypes as possible, certainly the most common serotypes and the serotypes associated with the most severe disease. Furthermore, the vaccines should be immunogenic in the major risk groups and, preferably, induce long-lasting immunity. ${ }^{26}$

\section{Pneumococcal vaccines and vaccination}

Two types of pneumococcal vaccines exist, which, from an immunological point of view, have a different mechanism of action depending on whether it is a polysaccharide or a so-called conjugate vaccine (Table 1). The difference in composition of the vaccines is that the polysaccharide vaccines contain a mixture of purified capsular polysaccharides, while the conjugate vaccines contain the capsular polysaccharides covalently linked (conjugated) to a protein carrier.

The current 23-valent polysaccharide vaccine (PPSV23) covers the largest number of serotypes. These 23 serotypes cause $85 \%-90 \%$ of the invasive pneumococcal pneumonia cases in adults in the USA and several other countries. ${ }^{27}$ The efficacy of PPSV23 in preventing CAP in adults is low (relative risk $0.54,95 \% \mathrm{CI}: 0.18-1.65) .{ }^{28}$ Theoretically, the capsular polysaccharides of all 93 serotypes would constitute an all-inclusive and, therefore, complete pneumococcal vaccine. There is, however, a maximum amount of polysaccharide that can be included in a single dosage, and that maximum is reached with 23 serotypes ( $25 \mu \mathrm{g}$ polysaccharide per serotype). In dose-response studies, it was found that a vaccine containing $12.5 \mu \mathrm{g}$ polysaccharide per serotype resulted in lower antibody titers than $25 \mu \mathrm{g} .{ }^{27}$

Table I Physical, chemical, and immunological characteristics of pneumococcal polysaccharides

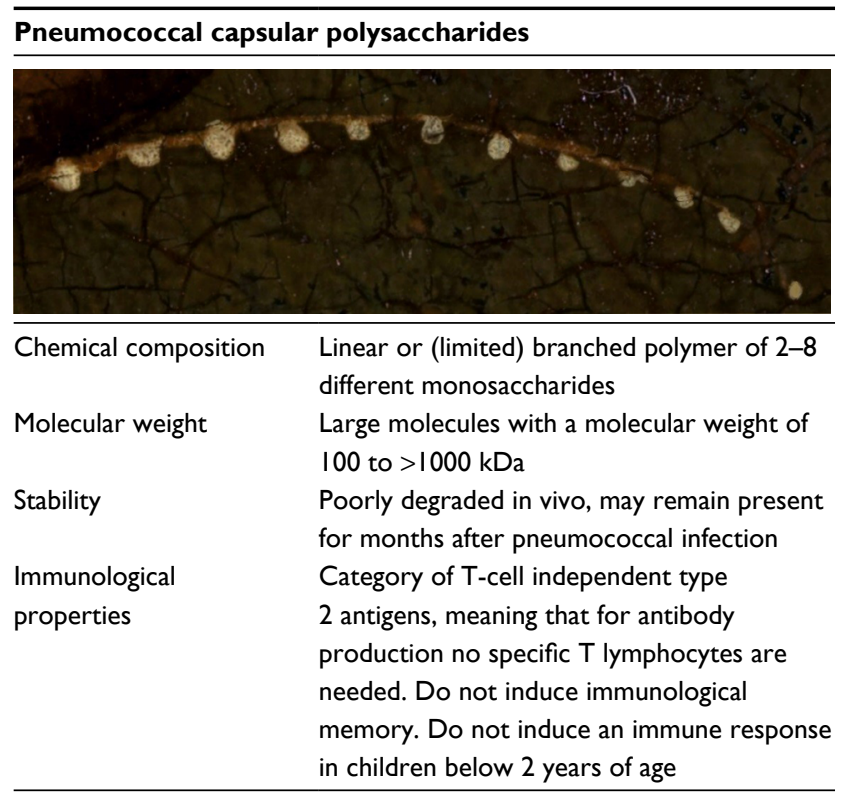

Notes: Data from reference. ${ }^{18}$ Artist impression of the structure of pneumococcal polysaccharide by Hieronimus Bosch. The Triptych of the Hermit Saints (1493), Gallerie dell'Accademia, Venice, Italy. ${ }^{120}$ 
Moreover, because of the so-called law of diminishing returns, addition of extra serotypes would not lead to a proportional increase in serotype coverage (Figure 2). The major drawbacks of PPSV23 are 2-fold: 1) this vaccine is not immunogenic in young children and 2) polysaccharide vaccines do not induce immunologic memory (Table 1). Both drawbacks of polysaccharide vaccines can be overcome by coupling of the polysaccharide to a protein carrier, pioneered by Avery and Goebel. ${ }^{29}$ This Nobel prize worthy discovery was made at a time when all medical research was focused on antibiotics; so, it took over half a century before the principles of Avery were put into practice for the production of polysaccharide conjugate vaccines. The first generation of pneumococcal conjugate vaccines was the 7-valent conjugate vaccine (PVC7), consisting of serotypes 4, 6B, 9V, 14, $18 \mathrm{C}, 19 \mathrm{~F}$, and $23 \mathrm{~F}$. This vaccine soon became a part of the standard vaccination schedules for children. After introduction of PCV7, a sharp decline in vaccine-serotype invasive pneumococcal disease was observed in children. ${ }^{30,31}$ Apart from protection against invasive disease, $\mathrm{PCV} 7$ also induced mucosal protection, reducing nasopharyngeal colonization and subsequently also reducing the transmission of vaccine serotypes to others. As a result, vaccine-type invasive pneumococcal disease also decreased in the unvaccinated community due to herd protection, particularly in the elderly $>65$ years of age..$^{32-34}$ The net benefit of PCV7 introduction was limited by the occurrence of the so-called replacement disease, which is invasive pneumococcal disease caused by serotypes not included in the vaccine. For example, 19A

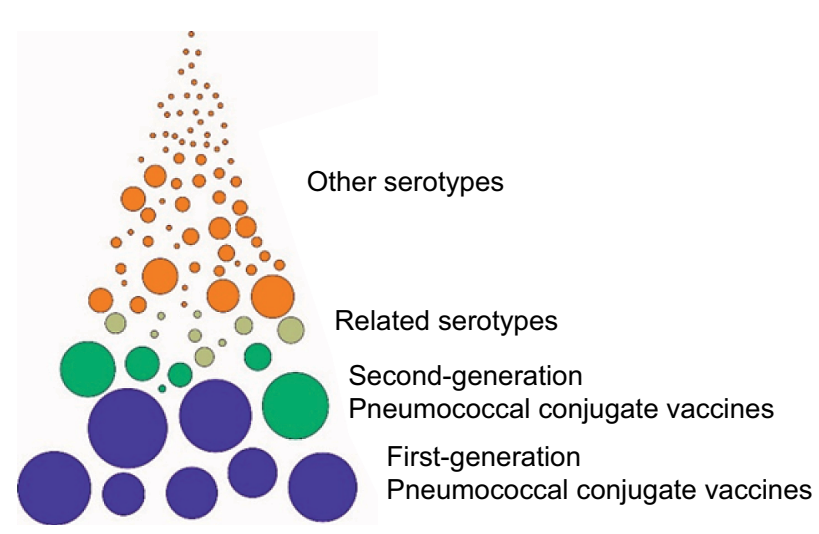

Figure 2 Pneumococcal serotypes and pneumococcal vaccines.

Notes: The first generation of pneumococcal conjugate vaccines (PCV7) consists of the serotypes $4,6 \mathrm{~B}, 9 \mathrm{~V}, 14,18 \mathrm{C}, 19 \mathrm{~F}$, and $23 \mathrm{~F}$. The second generation is PCV 10 (PCV7 serotypes + I, 5, 7F) and PCVI3 (PCVI0 serotypes + 3, 6A, 19A). Related serotypes belong to serogroups included in the conjugate vaccines. The size of the serotype circles is proportional to the frequency in invasive pneumococcal diseases in the Netherlands before the introduction of pneumococcal conjugate vaccination. Data from Rodenburg et al. ${ }^{119}$ became a frequently occurring serotype that induced CAP, the most frequent serotype in some populations. ${ }^{32-35}$ The fact that 19A became so prevalent while $19 \mathrm{~F}$ was incorporated in PCV7 came as a surprise. Up till that moment, it was assumed that antibodies against a serotype within one serogroup would lead to cross-protection: antibodies against $6 \mathrm{~A}$ would also protect against an infection with 6B. ${ }^{36-39}$ Apparently, cross protection within serogroups is not operational for serogroup $19 .{ }^{40}$ Replacement disease especially occurs in older adults and persons with comorbidity. Thus, large-scale implementation of PCV7 has dramatically changed the pneumococcal landscape through the direct effects in children and by indirect herd effects in nonvaccinated persons..$^{30,33,34}$ Serotype replacement disease, next to expanding the coverage, has been one of the arguments for development of 10- and 13-valent conjugate vaccines. ${ }^{41-43}$ These vaccines incorporate more of the most predominant serotypes, including the replacement serotypes (Figure 2). ${ }^{44-46}$ Also, after introduction of PCV13, serotype replacement continues. Across Europe, 24F and 15A now are the emerging serotypes not included in the PPSV23. ${ }^{47}$ In other continents, other serotypes may emerge, such as $23 \mathrm{~B}, 21$, and $35 \mathrm{~B}$ in the USA. ${ }^{48,49}$ The emerging serotypes in Europe, also including $22 \mathrm{~F}$ and 8 that are PPSV23 serotypes, appear to be less invasive with a relative low case: carrier ratio. ${ }^{47} \mathrm{It}$ is too early to tell whether these or other serotypes should be added to the next generation of PCVs. It is also too early to tell whether serotype replacement has come to an end or is still ongoing. At any rate, it is to be expected that the next generation of pneumococcal conjugate vaccines would need to have an expanded coverage. Multivalency ceiling, as discussed above for polysaccharide vaccines, is not an issue for PCV because in the conjugate vaccines, typically only $2-4 \mu \mathrm{g}$ of polysaccharide is used per serotype. A multivalency ceiling could exist when considering carrierspecific immune suppression (via carrier-induced epitopic suppression, high-dose tolerance as such, or otherwise). This phenomenon has been observed in clinical studies and was reviewed by Findlow and Borrow. ${ }^{50}$ The solution can be to use a carrier protein (or a combination of several different carrier proteins) different from other vaccine components.

\section{Pneumococcal vaccination in the elderly}

For the elderly (aged $\geq 65$ years), the recommended vaccine in terms of coverage is PPSV23. ${ }^{51}$ This vaccine does protect the elderly against invasive pneumococcal disease, but not completely. ${ }^{52-55}$ The reason(s) why polysaccharide vaccines 
have limited effectivity in the elderly is not entirely clear. A decline in functionality of the immune system could be one of the underlying mechanisms. In healthy elderly, both immunoglobulin (Ig) A and IgG anti-pneumococcal antibody levels have been shown to increase during the ages of 70-90. ${ }^{56}$ The functional antibody activity, as assessed by opsonophagocytosis, IgG antibody avidity, and passive protection in mice, however, is decreased in the elderly. ${ }^{57}$ These data suggest that even though there is an increase in the antibody titer, a reduction in the functionality of the antibodies occurs with age, which can explain the limited effectivity of PPSV23 in the elderly. Opsonophagocytosis is mediated primarily by neutrophils, which circulate through the bloodstream, phagocytosing and killing microbes. A decrease in the functional activity of neutrophils due to aging could therefore also contribute to increased vulnerability of the elderly. Indeed, neutrophils of the elderly population showed a significant decline in phagocytic killing of pneumococci opsonized with antibodies and complement. ${ }^{58}$ All these lead to a decline of the ability to generate an adequate immune response and thus increasing the susceptibility to bacterial infections, including pneumonia.

The term that has been coined to describe the declined functionality of the immune system in the elderly is immunosenescence, which is the accumulation of age-associated alterations that result in a progressive deterioration in the immune system. Immunosenescence and its associated chronic low-grade systemic "inflamm aging" contribute to the development and progression of pulmonary disease in older individuals. ${ }^{59-61}$ Many other alterations, which affect both the innate and adaptive immune systems, have been described, which cannot be addressed in detail in this review. ${ }^{62-66}$ All these lead to a decline of the ability to generate an adequate immune response and thus increasing the susceptibility to bacterial infections, including pneumonia. ${ }^{67}$

Whether the limited effectivity of pneumococcal polysaccharide vaccines in the elderly is due to immunosenescence, there is an obvious need for better vaccines for this risk category. The obvious choice would be a conjugate vaccine. In the Netherlands, the efficacy of PCV13 has been tested in older, but otherwise healthy adults. ${ }^{68}$ In a randomized, double-blind, placebo-controlled trial, over 80,000 participants $>65$ years of age were enrolled and followed-up for a period of maximum 2 years. ${ }^{69}$ For CAP caused by vaccine-type pneumococcal strains, the vaccine efficacy was $45.6 \%$ (95\% CI: $21.8-62.5$ ). For any pneumococcal CAP, vaccine efficacy was lower at 30.6\% (95\% CI: 9.8-46.7); for any-cause CAP, No protective effect was found for any-cause CAP, vaccine efficacy
$5.1 \%$ (95\% CI: -5.1 to 14.2$){ }^{69,70}$ Based on the outcome of this study, the current advice for vaccination of the elderly against CAP and other pneumococcal disease now tends to be the use of conjugate vaccines. ${ }^{71,72}$ Based on the data from the GRADE study, 1620 people would be needed to vaccinate (NNV) in order to prevent one case of hospitalized CAP. ${ }^{73}$ When taking into account the cumulative effect of preventing cases over a 5-year period, the NNV with PCV13 would be substantially lower at $576 .{ }^{74}$ Based on the CAPiTA study, an estimate was made of the quality-adjusted life years, costs of vaccination, and efficacy of the vaccine using incremental cost-effectiveness ratios. It was concluded that vaccination of high-risk individuals in the age category of 65-74 years is cost saving, and when medium-risk individuals aged 65-74 years are included, an incremental cost-effectiveness ratio of $€ 2900$ results. $^{75}$

\section{Outcome of pneumonia}

William Osler in his book, The Principles and Practice of Medicine (first edition published in 1892), summarizes the prognosis of pneumococcal pneumonia as follows: "In a disease which carries off one in every four or five of those attacked the prognosis in a large number of cases is necessarily grave" ${ }^{76}$ In the era before antibiotics were available, the overall mortality rate of pneumococcal pneumonia was $20 \%-25 \%$. Osler continues by pointing out the risk groups:

In children and in healthy adults the outlook is good. In the debilitated, in drunkards, and in the aged the chances are against recovery. So fatal is it in the latter class (the elderly) that it has been termed the natural end of the old man.

This latter sentence later was transformed into the saying "pneumonia is old man's friend". Risk groups for pneumococcal pneumonia, apart from the elderly, according to Osler, are the debilitated and drunkards. Chronic alcohol abuse indeed suppresses the immune system ${ }^{77}$ and may lead to a higher susceptibility for pneumococcal infections. ${ }^{78}$ Four out of the 6 observational studies found an increased risk for pneumococcal pneumonia in alcohol abusers (odds ratios ranging from 2.9 to 11.4$).{ }^{79} \mathrm{We}$ can only speculate whether the current recognized additional risk groups for pneumococcal pneumonia (chronic lung [including asthma], heart, liver, or kidney disease; diabetes; various types of cancer; absence of spleen; and smoking) could be grouped under the heading "debilitated" in Osler's time and age. ${ }^{80,81}$ In the song "Baby it's cold outside", written in 1944 by Frank Loesser for the movie Neptune's Daughter, the male singer appeals to a health risk of the woman he is trying to convince to stay with him:“[ $[.$. 
if you caught pneumonia and died [...]". The discovery and implementation of antibiotics offered adequate treatment options for pneumonia and greatly reduced the death rate. ${ }^{82}$ Modern hospitalization and adequate antibiotic treatment has resulted in a 30 -day survival of $>95 \%$ of the overall patient population admitted to the hospital with CAP, and thus, prognosis of pneumonia has improved tremendously. ${ }^{83}$

The vast majority of pneumonia deaths occur in the second- and third-world countries, but also in the USA, pneumonia remains the eigth leading cause of death, with 15.9 deaths per 100,000 population in 2014. Figures in Europe are also similar. ${ }^{84,85}$ Among infections, pneumonia is the leading cause of hospitalization and death for nursing home residents. ${ }^{86,87}$ Nursing home-acquired pneumonia patients show mortality rates as high as $40 \%$ of the patients who required hospitalization. ${ }^{88}$

The patients who survive hospitalization for CAP may still experience adverse outcomes after hospital discharge, and these include readmission and death due to a relapse of pneumonia or because of another cause. In the PORT cohort trial, 30\% of CAP patients had died after a median follow-up of 5.9 years. ${ }^{83}$ Risk factors for late mortality are increased age (>65 years of age), immune suppression, and cardiovascular disease. ${ }^{89-91}$ In our own studies, the (all-cause) long-term mortality of CAP patients is equally high: after 1 year, $17 \%$ of these patients have died, and after 5 years, it was $27 \% .^{92,93}$

Three scenarios can be envisioned on the relation between cardiovascular disease and CAP mortality. Preexisting cardiovascular disease as a comorbidity does have a negative impact on survival rates of CAP. ${ }^{94}$ In the second scenario, pneumococcal pneumonia can lead to a ventilation-perfusion mismatch pattern. ${ }^{95}$ This compromised state of oxygenation leads to an increase in myocardial oxygen demand and, as a result, stress on the myocardium. In the third scenario, the pneumococci invade the myocardium and form microlesions that cause cardiac dysfunction. ${ }^{96,97}$ The pneumococci that invade the myocardium form biofilms, making them resistant to antibiotic killing. Moreover, pneumococci that grow in biofilms release large amounts of pneumolysin, thereby killing resident cardiac macrophages and evading the host response. ${ }^{98} \mathrm{Via}$ any of these or other pathophysiologic events, major acute cardiac events could be induced. Indeed, patients with pneumococcal pneumonia are substantially more likely to experience simultaneous or subsequent acute cardiac events. ${ }^{99-101}$

In Osler's time, pneumococcal pneumonia was the natural end of the old man. Now, after more than a century of improved medical care, the long-term mortality figures seem to indicate that pneumococcal pneumonia predicts the natural end of the old man. From the above data, it is clear that cardiac involvement, either preexisting or induced, predicts a poor long-term outcome. Recent data from our own group indicate that, on top of and beyond classical pneumonia severity, scoring systems such as Curb65 and PSI, biomarkers for cardiac function (cardiac troponin T), are associated with long-term mortality. ${ }^{93}$ Future treatments aimed at preventing cardiovascular events could improve long-term survival of patients with pneumococcal pneumonia. ${ }^{102}$

\section{Costs of hospitalization}

Milder forms of CAP can be treated by the general practitioner or in an outpatient setting, but $\sim 20 \%-60 \%$ of CAP patients need to be hospitalized. The direct costs of hospitalization account for $56 \%$ of the economic burden of CAP in Europe. The remainder of the costs is caused by medication, outpatient care, and loss of workdays of the patients.

The average duration of a hospital stay for CAP varies between different countries. In the Netherlands, the mean hospitalization period was found to be 7.5-12.1 days; ${ }^{103,104}$ in the USA, a similar range of 4-12 days has been found. ${ }^{105-109}$ A comparison of hospitalization costs for CAP in various European countries and the USA shows great differences (Table 2). It has been recognized that comparision between several countries of the costs of hospitalization is difficult

Table 2 Costs of hospitalization of community-acquired pneumonia

\begin{tabular}{llll}
\hline Country & $\begin{array}{l}\text { Cost of } \\
\text { inpatient } \\
\text { hospitalization } \\
\text { (in dollars) }\end{array}$ & $\begin{array}{l}\text { GDP per } \\
\text { capita (in } \\
\text { dollars) }\end{array}$ & References \\
\hline Belgium & 6246 & 44,241 & 110 \\
The Czech Republic & 127 I & 19,703 & 111 \\
France & 6406 & 40,667 & 110 \\
Germany & 5308 & 42,482 & 110 \\
Greece & 2740 & 26,782 & 110 \\
Hungary & 1040 & 13,007 & 111 \\
Italy & 5464 & 35,663 & 110 \\
the Netherlands & $6060-13,6$ II & 50,289 & $104,107,110,116$ \\
Poland & 740 & 12,426 & 111 \\
Portugal & 2933 & 22,514 & 110 \\
Slovakia & 1752 & 16,553 & 110 \\
Spain & 4297 & 30,720 & 110 \\
Turkey & 1129 & 10,111 & 110 \\
UK & 4063 & 38,741 & 110 \\
USA & $9492-43,611$ & 48,291 & $112-115$ \\
\hline Note: GDP & & & \\
\hline
\end{tabular}

Note: GDP per capita (20I0). Data from UN Data. ${ }^{12}$

Abbreviation: GDP, gross domestic product. 
to nearly impossible due to different settings and healthcare systems. ${ }^{117}$ Even within a given country, substantial differences can be found, as is evident from Table 2 for the range in hospitalization costs within the Netherlands and the USA. Characteristics of the patient population (age and comorbidities), severity of CAP in relation to intensive care unit (ICU) admission, length of hospital stay, and level of the hospital (second or third level) contribute to this variation. Particularly, the length of a hospital stay is a major cost driver because a general ward stay amounts to $57 \%$ of the total hospital costs, followed by ICU nursing with $16 \% .{ }^{116}$ From such a cost breakdown, it also becomes clear that treatment strategies that result in a reduction of the length of stay lead to a substantial reduction in costs. ${ }^{103}$

With an ongoing increase in life expectancy and an aging population in general, the costs of hospitalization probably will increase further in the future. These trends will also affect the cost-effectiveness of preventive measures such as vaccination.

\section{Conclusion}

Pneumococcal pneumonia was and still remains a serious disease that mainly affects young children and the elderly. Despite adequate antibiotic treatment, the long-term mortality of pneumococcal pneumonia remains high. Preventive measures therefore are warranted. Pneumococcal conjugate vaccination can prevent invasive and mucosal pneumococcal diseases in children and also in the elderly. It should be recognized that the serotype composition of current pneumococcal conjugate vaccines is not tailored for the elderly, and that replacement disease still could occur. Yet the 13-valent conjugate vaccine has been shown to be protective against the vaccine-included serotypes. Long-term mortality of pneumococcal pneumonia should be included in policy making about introduction of these vaccines for the elderly.

In the painting, The Triptych of the Hermit Saints (Figure 3), St. Jerome, St. Antony, and St. Giles are depicted on the 3 separate panels. All the 3 Saints are old men, a risk group for pneumococcal pneumonia. The Triptych is a painting of Hieronimus Bosch, one of the greatest Dutch painters. All of his paintings depict scenes beyond imagination, and even 600 years after his death, the debates on the interpretation of his works continues. Triptych of the Hermit Saints is on permanent display in the Gallerie dell'Accademia, Venice, Italy, but was brought to "“s Hertogenbosch in 2016 on the occasion of Bosch" 600th anniversary. The center panel depicts St. Jerome kneeling in a desert-like landscape and surrounded by symbols of evil. In the left panel, St. Anthony, the

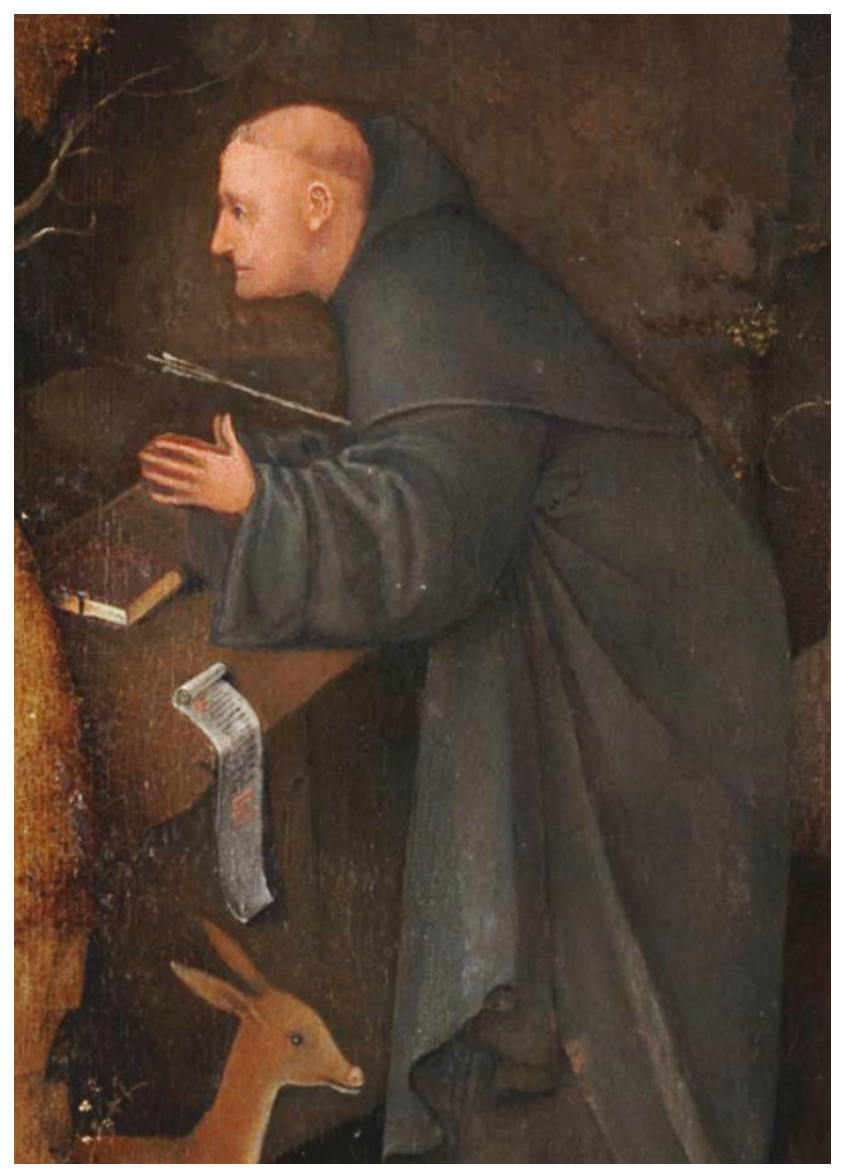

Figure 3 Detail of the right panel of The Triptych of the Hermit Saints by Hieronymus Bosch (1493), Gallerie dell'Accademia, Venice, Italy. Note: Reprinted from Wikimedia Commons. ${ }^{120}$

Abbot, is situated in a landscape that has in the background, a burning village. Also, he is surrounded by demons of all sorts. The third hermit, St. Giles, in the right-hand panel clearly stands out. He is praying in his cave and appears to be at total ease, although he has been shot by an arrow. It does not take much imagination (or a bit of bias) to envision the arrow as the syringe by which St. Giles has been vaccinated. For that reason, he is immune against the great variety of demons that also surround him. The variety of demons represent, of course, all the serotypes of pneumococci. On the desk of St. Giles, we see a book of prayers and a roll of paper with something written on it. Maybe, they are the names of other people and other saints, saved thanks to vaccination.

In times of despair, St. Giles, as a patron saint, is called upon in case of infectious disease, either acute or chronic, both for the elderly as for the (very) young. It has to be admitted that, also in case of drought, idiocy, or marital infertility, St. Giles is called upon for help. At any rate, in order to be protected against $S$. pneumoniae, it is better to be vaccinated than to rely on protection by St. Gilles. 


\section{Acknowledgment}

GT Rijkers reports receiving grants from Pfizer for research on pneumococcal vaccines and lecturing fees from Pfizer and GlaxoSmithKline.

\section{Disclosure}

The authors report no conflicts of interest in this work.

\section{References}

1. Hendley JO. Clinical practice. Otitis media. N Engl J Med. 2002; 347(15):1169-1174.

2. https://www.who.int/immunization/monitoring_surveillance/burden/ estimates/Pneumo_hib/en/. Accessed October 16, 2017.

3. https://www.who.int/medicines/areas/priority_medicines/ Ch6_22Pneumo.pdf. Accessed October 16, 2017.

4. Dochez AR, Avery OT. Varieties of pneumococcus and their relation to lobar pneumonia. J Exp Med. 1915;21:114-132.

5. Heffron R. Pneumonia, with Special Reference to Pneumococcus Lobar Pneumonia. Cambridge, MA: Harvard University Press; 1939.

6. Drijkoningen JJ, Rohde GG. Pneumococcal infection in adults: burden of disease. Clin Microbiol Infect. 2014;20(Suppl 5):45-51.

7. Welte T, Torres A, Nathwani D. Clinical and economic burden of community-acquired pneumonia among adults in Europe. Thorax. 2012;67:71-79.

8. Endeman H, Schelfhout V, Voorn GP, van Velzen-Blad H, Grutters JC, Biesma DH. Clinical features predicting failure of pathogen identification in patients with community acquired pneumonia. Scand J Infect Dis. 2008;40:715-720.

9. Pride MW, Huijts SM, Wu K, et al. Validation of an immunodiagnostic assay for detection of 13 Streptococcus pneumoniae serotype-specific polysaccharides in human urine. Clin Vaccine Immunol. 2012; 19(8):1131-1141.

10. Huijts SM, Pride MW, Vos JM, et al. Diagnostic accuracy of a serotypespecific antigen test in community-acquired pneumonia. Eur Respir J. 2013;42(5):1283-1290.

11. van Mens SP, Meijvis SC, Endeman H, et al. Longitudinal analysis of pneumococcal antibodies during community-acquired pneumonia reveals a much higher involvement of Streptococcus pneumoniae than estimated by conventional methods alone. Clin Vaccine Immunol. 2011;18(5):796-801.

12. Rendon A, Rendon-Ramirez EJ, Rosas-Taraco AG. Relevant cytokines in the management of community-acquired pneumonia. Curr Infect Dis Rep. 2016;18:10.

13. McCulloh RJ, Patel K. Recent developments in pediatric communityacquired pneumonia. Curr Infect Dis Rep. 2016;18:14.

14. Pletz MW, Rohde GG, Welte T, Kolditz M, Ott S. Advances in the prevention, management, and treatment of community-acquired pneumonia. F1000Res. 2016;5:300.

15. Woodhead M, Blasi F, Ewig S, et al. Guidelines for the management of adult lower respiratory tract infections - full version. Clin Microbiol Infect. 2011;17(Suppl 6):E1-E59.

16. Aliberti S, Kaye KS. The changing microbiologic epidemiology of community-acquired pneumonia. Postgrad Med. 2013;125(6):31-42.

17. Hernes SS, Hagen E, Tofteland S, et al. Transthoracic fine-needle aspiration in the aetiological diagnosis of community-acquired pneumonia. Clin Microbiol Infect. 2010;16(7):909-911.

18. Ideh RC, Howie SR, Ebruke B, et al. Transthoracic lung aspiration for the aetiological diagnosis of pneumonia: 25 years of experience from The Gambia. Int J Tuberc Lung Dis. 2011;15(6):729-735.

19. Scott JA, Hall AJ. The value and complications of percutaneous transthoracic lung aspiration for the etiologic diagnosis of communityacquired pneumonia. Chest. 1999;116(6):1716-1732.

20. Geno KA, Gilbert GL, Song JY, et al. Pneumococcal capsules and their types: past, present, and future. Clin Microbiol Rev. 2015;28(3):871-899.
21. Fedson DS, Nicolas-Spony L, Klemets P, et al. Pneumococcal polysaccharide vaccination for adults: new perspectives for Europe. Expert Rev Vaccines. 2011;10:1143-1167.

22. Hausdorff WP, Bryant J, Kloek C, Paradiso PR, Siber GR. The contribution of specific pneumococcal serogroups to different disease manifestations: implications for conjugate vaccine formulation and use, part II. Clin Infect Dis. 2000;30:122-140.

23. Tan TQ, Mason EO Jr, Wald ER, et al. Clinical characteristics of children with complicated pneumonia caused by Streptococcus pneumoniae. Pediatrics. 2002;110:1-6.

24. Imöhl M, Reinert RR, Ocklenburg C, van der Linden M. Association of serotypes of Streptococcus pneumoniae with age in invasive pneumococcal disease. J Clin Microbiol. 2010;48(4):1291-1296.

25. Hachel M, Lascols C, Bouchillon S, Hilton B, Morgenstern D, Purdy J. Serotype prevalence and antibiotic resistance in Streptococcus pneumoniae clinical isolates among global population. Vaccine. 2013;31: 4881-4887.

26. Aliberti S, Mantero M, Mirsaeidi M, Blasi F. The role of vaccination in preventing pneumococcal disease in adults. Clin Microbiol Infect. 2014; 20(Suppl 5):52-58.

27. Robbins JB, Austrian R, Lee CJ, et al. Considerations for formulating the second-generation pneumococcal capsular polysaccharide vaccine with emphasis on the cross-reactive types within groups. J Infect Dis. 1983; 148:1136-1159.

28. Diao WQ, Shen N, Yu PX, Liu BB, He B. Efficacy of 23-valent pneumococcal polysaccharide vaccine in preventing community-acquired pneumonia among immunocompetent adults: a systematic review and meta-analysis of randomized trials. Vaccine. 2016;34:1496-1503.

29. Avery O, Goebel WF. Chemo-immunological studies on conjugated carbohydrate-proteins. II. Immunological specificity of synthetic sugar protein antigens. $J$ Exp Med. 1929;50:533-550.

30. Whitney CG, Farley MM, Hadler J, et al. Decline in invasive pneumococcal disease after the introduction of protein-polysaccharide conjugate vaccine. N Engl J Med. 2003;348(18):1737-1746.

31. Fitzwater SP, Chandran A, Santosham M, Johnson HL. The worldwide impact of the seven-valent pneumococcal conjugate vaccine. Pediatr Infect Dis J. 2012;31(5):501-508.

32. Lexau CA, Lynfield R, Danila R et al; Active Bacterial Core Surveillance Team. Changing epidemiology of invasive pneumococcal disease among older adults in the era of pediatric pneumococcal conjugate vaccine. JAMA. 2005;294(16):2043-2051.

33. van Deursen AM, van Mens SP, Sanders EA et al; Invasive Pneumococcal Disease Sentinel Surveillance Laboratory Group. Invasive pneumococcal disease and 7-valent pneumococcal conjugate vaccine, the Netherlands. Emerg Infect Dis. 2012;18(11):1729-1737.

34. Myint TT, Madhava H, Balmer P, et al. The impact of 7-valent pneumococcal conjugate vaccine on invasive pneumococcal disease: a literature review. Adv Ther. 2013;30(2):127-151.

35. Dagan R. Serotype replacement in perspective. Vaccine. 2009;27(Suppl 3): $\mathrm{C} 22-\mathrm{C} 24$

36. Vestrheim DF, Steinbakk M, Aaberge IS, Caugant DA. Postvaccination increase in serotype 19A pneumococcal disease in Norway is driven by expansion of penicillin-susceptible strains of the ST199 complex. Clin Vaccine Immunol. 2012;19(3):443-445.

37. Scott JR, Hanage WP, Lipsitch M, et al. Pneumococcal sequence type replacement among American Indian children: a comparison of preand routine-PCV7 eras. Vaccine. 2012;30(13):2376-2381.

38. Miller E, Andrews NJ, Waight PA, Slack MP, George RC. Herd immunity and serotype replacement 4 years after seven-valent pneumococcal conjugate vaccination in England and Wales: an observational cohort study. Lancet Infect Dis. 2011;11(10):760-768.

39. Kim HW, Lee S, Kim KH. Serotype 6B from a pneumococcal polysaccharide vaccine induces cross-functional antibody responses in adults to serotypes 6A, 6C, and 6D. Medicine (Baltimore). 2016;95(37):e4854.

40. Grant LR, O'Brien SE, Burbidge P, et al. Comparative immunogenicity of 7 and 13-valent pneumococcal conjugate vaccines and the development of functional antibodies to cross-reactive serotypes. PLoS One. 2013;8(9):e74906. 
41. Vesikari T, Karvonen A, Korhonen T, et al. Immunogenicity of 10-valent pneumococcal nontypeable Haemophilus influenzae Protein D Conjugate Vaccine when administered as catch-up vaccination to children 7 months to 5 years of age. Pediatr Infect Dis J. 2011;30(8):e130-e141.

42. Lee H, Choi EH, Lee HJ. Efficacy and effectiveness of extendedvalency pneumococcal conjugate vaccines. Korean J Pediatr. 2014;57(2):55-66.

43. Adler H, Ferreira DM, Gordon SB, Rylance J. Pneumococcal capsular polysaccharide immunity in the elderly. Clin Vaccine Immunol. 2017;24(6):e00004-e00017.

44. Principi N, Esposito S. Development of pneumococcal vaccines over the last 10 years. Expert Opin Biol Ther. 2018;18(1):7-17.

45. Rijkers GT. Fixing a hole: preventing pneumococcal pneumonia by vaccination. Front Immunol. 2016;7:349.

46. Rijkers GT, van Mens SP, van Velzen-Blad H. What do the next 100 years hold for pneumococcal vaccination? Expert Rev Vaccines. 2010;9(11):1241-1244.

47. Tin Tin Htar M, Christopoulou D, Schmitt HJ. Pneumococcal serotype evolution in Western Europe. BMC Infect Dis. 2015;15:419.

48. Kaur R, Casey JR, Pichichero ME. Emerging Streptococcus pneumoniae strains colonizing the nasopharynx in children after 13-valent pneumococcal conjugate vaccination in comparison to the 7-valent era, 2006-2015. Pediatr Infect Dis J. 2016;35:901-916.

49. Richter SS, Diekema DJ, Heilmann KP, Dohrn CL, Riahi F, Doern GV. Changes in pneumococcal serotypes and antimicrobial resistance after introduction of the 13-valent conjugate vaccine in the United States. Antimicrob Agents Chemother. 2014;58:6484-6489.

50. Findlow H, Borrow R. Interactions of conjugate vaccines and coadministered vaccines. Hum Vaccin Immunother. 2016;12:226-230.

51. Recommended Adult Immunization Schedule, by Vaccine and Age Group. Centers for Disease Control and Prevention: Atlanta, GA; 2015.

52. Maruyama T, Taguchi O, Niederman MS, et al. Efficacy of 23-valent pneumococcal vaccine in preventing pneumonia and improving survival in nursing home residents: double blind, randomised and placebo controlled trial. BMJ 2010;340:c1004.

53. Leventer-Roberts M, Feldman BS, Brufman I, Cohen-Stavi CJ, Hoshen M, Balicer RD. Effectiveness of 23-valent pneumococcal polysaccharide vaccine against invasive disease and hospital-treated pneumonia among people aged $\geq 65$ years: a retrospective case-control study. Clin Infect Dis. 2015;60(10):1472-1480.

54. Ochoa-Gondar O, Vila-Corcoles A, Rodriguez-Blanco T, et al. Effectiveness of the 23 -valent pneumococcal polysaccharide vaccine against community-acquired pneumonia in the general population aged $\geq 60$ years: 3 years of follow-up in the CAPAMIS study. Clin Infect Dis. 2014;58(7):909-917.

55. Rijkers GT. Pneumococcal vaccination in elderly. In: Pneumococcal Conjugate Vaccines, Future Medicine. London, UK; 2012:32-45.

56. Bátory G, Jancsó A, Puskás E, Rédei A, Lengyel E. Antibody and immunoglobulin levels in aged humans. Arch Gerontol Geriatr. 1984;3(2):175-188.

57. Romero-Steiner S, Musher DM, Cetron MS, et al. Reduction in functional antibody activity against Streptococcus pneumoniae in vaccinated elderly individuals highly correlates with decreased IgG antibody avidity. Clin Infect Dis. 1999;29(2):281-288.

58. Simell B, Vuorela A, Ekström N, et al. Aging reduces the functionality of anti-pneumococcal antibodies and the killing of Streptococcus pneumoniae by neutrophil phagocytosis. Vaccine. 2011;29(10) 1929-1934.

59. Murray MA, Chotirmall SH. The impact of immunosenescence on pulmonary disease. Mediators Inflamm. 2015;2015:692546.

60. Pera A, Campos C, López N, et al. Immunosenescence: implications for response to infection and vaccination in older people. Maturitas 2015;82(1):50-55.

61. Kovacs EJ, Boe DM, Boule LA, Curtis BJ. Inflammaging and the lung. Clin Geriatr Med. 2017;33(4):459-471.
62. Lee S, Kim HW, Lee JH, Kim KH. Functional immune responses to 11 non-PCV13 serotypes after immunization with a 23-valent pneumococcal polysaccharide vaccine in older adults. Vaccine. 2017;35(37):4960-4965

63. van de Vosse E, van Ostaijen-Ten Dam MM, Vermaire R, et al. Recurrent respiratory tract infections (RRTI) in the elderly: a late onset mild immunodeficiency? Clin Immunol. 2017;180:111-1119.

64. Roth A, Glaesener S, Schütz K, Meyer-Bahlburg A. Reduced number of transitional and naive B cells in addition to decreased BAFF levels in response to the $\mathrm{T}$ cell independent immunogen Pneumovax ${ }^{\circledR} 23$. PLoS One. 2016;11(3):e0152215.

65. Heaney JL, Phillips AC, Carroll D, Drayson MT. Salivary functional antibody secretion is reduced in older adults: a potential mechanism of increased susceptibility to bacterial infection in the elderly. J Gerontol A Biol Sci Med Sci. 2015;70(12):1578-1585.

66. Ahn JG, Kim HW, Choi HJ, Lee JH, Kim KH. Functional immune responses to twelve serotypes after immunization with a 23-valent pneumococcal polysaccharide vaccine in older adults. Vaccine. 2015;33(38):4770-4775

67. Aw D, Silva AB, Palmer DB. Immunosenescence: emerging challenges for an ageing population. Immunology. 2007;120(4):435-446.

68. Hak E, Grobbee DE, Sanders EA, et al. Rationale and design of CAPITA: a RCT of 13-valent conjugated pneumococcal vaccine efficacy among older adults. Neth J Med. 2008;66(9):378-383.

69. Bonten MJ, Huijts SM, Bolkenbaas M, et al. Polysaccharide conjugate vaccine against pneumococcal pneumonia in adults. $N$ Engl J Med. 2015;372(12):1114-1125.

70. van Werkhoven $\mathrm{CH}$, Bonten MJ. The Community-Acquired Pneumonia immunization Trial in Adults (CAPiTA): what is the future of pneumococcal conjugate vaccination in elderly? Future Microbiol. 2015;10(9):1405-1413.

71. Black CL, Williams WW, Warnock R, et al. Pneumococcal vaccination among Medicare beneficiaries occurring after the advisory committee on immunization practices recommendation for routine use of 13-valent pneumococcal conjugate vaccine and 23-valent pneumococcal polysaccharide vaccine for adults aged $\geq 65$ years. MMWR Morb Mortal Wkly Rep. 2017;66(27):728-733.

72. Dirmesropian S, Wood JG, MacIntyre CR, et al. Cost-effectiveness of 13-valent pneumococcal conjugate vaccine (PCV13) in older Australians. Vaccine. 2017;35(34):4307-4314.

73. Advisory Committee on Immunization Practices. Grading of Recommendations, Assessment, Development, and Evaluation (GRADE) for pneumococcal vaccines for adults aged $\geq 65$ years. US Department of Health \& Human Services. Available from: https://www-cdc-gov. proxy.library.uu.nl/vaccines/acip/recs/grade/pneumo-vac-adult.html. Accessed September 29, 2017.

74. McLaughlin JM, Swerdlow DL, Isturiz RE, Jodar L. Rethinking number-needed-to-vaccinate for pneumococcal conjugate vaccines in older adults: current and future implications. Vaccine. 2017;35(40):5360-5365.

75. Mangen MJ, Rozenbaum MH, Huijts SM, et al. Cost-effectiveness of adult pneumococcal conjugate vaccination in the Netherlands. Eur Respir J. 2015;46(5):1407-1416.

76. Osler W. The Principles and Practice of Medicine. Available from: https://archive.org/details/principlesandpr00mccrgoog. Accessed September 29, 2017.

77. Cook RT. Alcohol abuse, alcoholism, and damage to the immune system-a review. Alcohol Clin Exp Res. 1998;22(9):1927-1942.

78. Rush B. Effects of Ardent Spirits upon the Human Body and Mind, with an Account of the Means of Preventing and of the Remedies for Curing Them. Philadelphia, PA: Thomas Dobson; 1810.

79. Cruickshank HC, Jefferies JM, Clarke SC. Lifestyle risk factors for invasive pneumococcal disease: a systematic review. BMJ Open. 201420;4(6):e005224.

80. Ruiz M, Ewig S, Torres A, et al. Severe community-acquired pneumonia. Risk factors and follow-up epidemiology. Am J Respir Crit Care Med. 1999;160(3):923-929. 
81. Almirall J, Serra-Prat M, Bolíbar I, Balasso V. Risk factors for community-acquired pneumonia in adults: a systematic review of observational studies. Respiration. 2017;94(3):299-311.

82. Podolsky SH. The changing fate of pneumonia as a public health concern in 20th-century America and beyond. Am J Public Health. 2005;95(12):2144-2154.

83. Mortensen EM, Kapoor WN, Chang CC, Fine MJ. Assessment of mortality after long-term follow-up of patients with community-acquired pneumonia. Clin Infect Dis. 2003;37(12):1617-1624.

84. https://www.cdc.gov/nchs/data/nvsr/nvsr65/nvsr65_04.pdf. Assessed October 19, 2017.

85. https://www.who.int/medicines/areas/priority_medicines/ Ch6_22Pneumo.pdf. Assessed October 19, 2017.

86. Beck-Sague C, Banerjee S, Jarvis WR. Infectious diseases and mortality among US nursing home residents. Am J Public Health. 1993;83(12):1739-1742.

87. Dhawan N, Pandya N, Khalili M, et al. Predictors of mortality for nursing home-acquired pneumonia: a systematic review. Biomed Res Int. 2015;2015:285983.

88. Marrie TJ. Pneumonia. Clin Geriatr Med. 1992;8(4):721-734.

89. Corrales-Medina VF, Musher DM, Shachkina S, Chirinos JA. Acute pneumonia and the cardiovascular system. Lancet. 2013;381(9865):496-505.

90. Ramirez J, Aliberti S, Mirsaeidi M, et al. Acute myocardial infarction in hospitalized patients with community-acquired pneumonia. Clin Infect Dis. 2008;47(2):182-187.

91. Mortensen EM, Metersky ML. Long-term mortality after pneumonia. Semin Respir Crit Care Med. 2012;33(3):319-324.

92. Wagenvoort GH, Sanders EA, de Melker HE, van der Ende A, Vlaminckx BJ, Knol MJ. Long-term mortality after IPD and bacteremic versus non-bacteremic pneumococcal pneumonia. Vaccine. 2017;35(14):1749-1757.

93. Vestjens SMT, Spoorenberg SMC, Rijkers GT, et al. High-sensitivity cardiac troponin T predicts mortality after hospitalization for community-acquired pneumonia. Respirology. 2017;22(5):1000-1006.

94. Carbon C. Optimal treatment strategies for community-acquired pneumonia: high-risk patients (geriatric and with comorbidity). Chemotherapy. 2001;47(Suppl 4):19-25.

95. Bajc M, Neilly B, Miniati M, Mortensen J, Jonson B. Methodology for ventilation/perfusion SPECT. Semin Nucl Med. 2010;40(6):415-425.

96. Brown AO, Orihuela CJ. Visualization of Streptococcus pneumoniae within cardiac microlesions and subsequent cardiac remodeling. JVis Exp. 2015;98.

97. Brown AO, Mann B, Gao G, et al. Streptococcus pneumoniae translocates into the myocardium and forms unique microlesions that disrupt cardiac function. PLoS Pathog. 2014;10(9):e1004383.

98. Shenoy AT, Brissac T, Gilley RP, et al. Streptococcus pneumoniae in the heart subvert the host response through biofilm-mediated resident macrophage killing. PLoS Pathog. 2017;13(8):e1006582.

99. Reyes LF, Restrepo MI, Hinojosa CA, et al. Severe pneumococcal pneumonia causes acute cardiac toxicity and subsequent cardiac remodeling. Am J Respir Crit Care Med. 2017;196(5):609-620.

100. Musher DM, Rueda AM, Kaka AS, Mapara SM. The association between pneumococcal pneumonia and acute cardiac events. Clin Infect Dis. 2007;45(2):158-165.

101. Perry TW, Pugh MJ, Waterer GW, et al. Incidence of cardiovascular events after hospital admission for pneumonia. Am J Med. 2011;124(3):244-251.

102. Feldman C, Anderson R. Prevalence, pathogenesis, therapy, and prevention of cardiovascular events in patients with community-acquired pneumonia. Pneumonia. 2016;8:11.
103. Meijvis SC, Hardeman H, Remmelts HH, et al. Dexamethasone and length of hospital stay in patients with community-acquired pneumonia: a randomised, double-blind, placebo-controlled trial. Lancet. 2011;377(9782):2023-2030.

104. Vissink CE, Huijts SM, de Wit GA, Bonten MJ, Mangen MJ. Hospitalization costs for community-acquired pneumonia in Dutch elderly: an observational study. BMC Infect Dis. 2016;16:466.

105. Kaplan V, Angus DC, Griffin M, Clermont G, Watson RS, LindeZwirble WT. Hospitalized community-acquired pneumonia in the elderly: age- and sex-related patterns of care and outcome in the United States. Am J Respir Crit Care Med. 2002;165:766-772.

106. DeFrances CJ, Lucas CA, Bule VC, Golosinskiy A. 2006 National Hospital discharge survey. Natl Health Stat Rep. 2008;30:1-20.

107. Metersky ML, Ma A, Houck PM, Bratzler DW. Antibiotics for bacteremic pneumonia: improved outcomes with macrolides but not fluoroquinolones. Chest. 2007;131:466-473.

108. Restrepo MI, Mortensen EM, Velez JA, Frei C, Anzueto A. A comparative study of community-acquired pneumonia patients admitted to the ward and the ICU. Chest. 2008;133:610-617.

109. Hall MJ, DeFrances CJ, Williams SN, et al. National Hospital Discharge survey: 2007 summary. Natl Health Stat Report. 2010;29:1-21.

110. Ostermann H, Garau J, Medina J, Pascual E, McBride K, Blasi F; REACH study group. Resource use by patients hospitalized with community-acquired pneumonia in Europe: analysis of the REACH study. BMC Pulm Med. 2014;14:36.

111. Tichopad A, Roberts C, Gembula I, et al. Clinical and economic burden of community-acquired pneumonia among adults in the Czech Republic, Hungary, Poland and Slovakia. PLoS One. 2013;8(8):e71375.

112. Sato R, Gomez Rey G, Nelson S, Pinsky B. Community-acquired pneumonia episode costs by age and risk in commercially insured US adults aged $\geq 50$ years. Appl Health Econ Health Policy. 2013;11(3):251-258.

113. Yu H, Rubin J, Dunning S, Li S, Sato R. Clinical and economic burden of community-acquired pneumonia in the Medicare fee-for-service population. J Am Geriatr Soc. 2012;60(11):2137-2143.

114. Thomas CP, Ryan M, Chapman JD, et al. Incidence and cost of pneumonia in medicare beneficiaries. Chest. 2012;142(4):973-981.

115. Jacob C, Mittendorf T, Graf von der Schulenburg JM. Krankheitskosten sowie gesundheitsbezogene Lebensqualität (hrQoL) bei ambulant erworbener Pneumonie (CAP) - ein systematisches [Costs of illness and health-related quality of life for community-acquired pneumonia-a systematic review.] Pneumologie. 2011;65(8):498-502. German.

116. Spoorenberg SM, Bos WJ, Heijligenberg R et al. Microbial aetiology, outcomes, and costs of hospitalisation for community-acquired pneumonia; an observational analysis. BMC Infect Dis. 2014;14:335.

117. Welte R, Feenstra T, Jager H, Leidl R. A decision chart for assessing and improving the transferability of economic evaluation results between countries. Pharmacoeconomics. 2004;22(13):857-876.

118. Peeters CC, Tenbergen-Meekes AM, Haagmans B, et al. Pneumococcal conjugate vaccines. Immunol Lett. 1991;30(2):267-274.

119. Rodenburg GD, de Greeff SC, Jansen AG, et al. Effects of pneumococcal conjugate vaccine 2 years after its introduction, the Netherlands. Emerg Infect Dis. 2010;16(5):816-823.

120. Wikimedia Commons [homepage on the internet]. Jheronimus Bosch Gallery. 2.1.17 The Hermit Saints Triptych. Available from: https://commons.wikimedia.org/wiki/Jheronimus_Bosch\#The_Hermit_Saints_Triptych. Accessed March 9, 2018.

121. UN Data [homepage on the internet]. Per capita GDP at current prices. Available from: http://data.un.org/Data.aspx?q=GDP+per+capita\&d $=$ SNAAMA $\& \mathrm{f}=$ grID $\% 3 \mathrm{a} 101 \% 3 \mathrm{bcurrID} \% 3 \mathrm{aUSD} \% 3 \mathrm{bpcFlag} \% 3 \mathrm{a} 1$. Accessed March 9, 2018. 


\section{Publish your work in this journal}

Risk Management and Healthcare Policy is an international, peer-reviewed open access journal focusing on all aspects of public health, policy, and preventative measures to promote good health and improve morbidity and mortality in the population. The journal welcomes submitted papers covering original research, basic science, clinical and epidemiological

Submit your manuscript here: https://www.dovepress.com/risk-management-and-healthcare-policy-journal

studies, reviews and evaluations, guidelines, expert opinion and commentary, case reports and extended reports. The manuscript management system is completely online and includes a very quick and fair peerreview system, which is all easy to use. Visit http://www.dovepress.com/ testimonials.php to read real quotes from published authors. 